\title{
Incidence of lymph node metastasis from early gastric cancer: estimation with a large number of cases at two large centers
}

\author{
Takuji Gotoda ${ }^{1}$, Akio Yanagisawa ${ }^{2}$, Mitsuru Sasako ${ }^{3}$, Hiroyuki Ono ${ }^{1}$, Yukihiro Nakanishi ${ }^{4}$, \\ TADAKAZU SHIMODA ${ }^{5}$, and Yo KATO ${ }^{2}$ \\ ${ }^{1}$ Department of Endoscopy, National Cancer Center Hospital, Tokyo, Japan \\ ${ }^{2}$ Department of Pathology, Cancer Institute, Tokyo, Japan \\ ${ }^{3}$ Department of Surgical Oncology, National Cancer Center Hospital, 5-1-1 Tsukiji, Chuo-ku, Tokyo 104-0045, Japan \\ ${ }^{4}$ Pathology Division, National Cancer Center Research Institute, Tokyo, Japan \\ ${ }^{5}$ Department of Clinical Laboratory, National Cancer Center Hospital, Tokyo, Japan
}

\begin{abstract}
Background. The presence of lymph node metastasis (LNM) is the most important prognostic factor for patients with early gastric cancer (EGC). A D2 gastrectomy has been the gold standard treatment. Strict criteria for endoscopic mucosal resection have been widely accepted in Japan. There are some trials aimed at expanding the indications for local treatment, although there has not been a comprehensive review of the risk of LNM with the lesions of EGC.

Methods. We investigated 5265 patients who had undergone gastrectomy with lymph node dissection for EGC at the National Cancer Center Hospital and the Cancer Institute Hospital. Nine clinicopathological factors were assessed for their possible association with LNM.

Results. None of the 1230 well differentiated intramucosal cancers of less than $30 \mathrm{~mm}$ diameter regardless of ulceration findings, were associated with metastases $(95 \%$ confidence interval [CI], 0- $0.3 \%)$. None of the 929 lesions without ulceration were associated with nodal metastases $(95 \%$ CI, 0- $\mathbf{0 . 4 \%}$ ) regardless of tumor size. Similarly to findings for intramucosal cancers, for submucosal lesions, there was a significant correlation between tumor size larger than $30 \mathrm{~mm}$ and lymphatic-vascular involvement with an increased risk of LNM. None of the $\mathbf{1 4 5}$ differentiated adenocarcinomas of less than 30-mm-diameter without lymphatic or venous permeation were associated with LNM, provided that the lesion had invaded less than $500 \mu \mathrm{m}$ into the submucosa $(95 \% \mathrm{CI}$, 0-2.5\%).

Conclusion. Based on our large series of cases, we have been able to clarify the risks associated with EGC and to propose expansion of the criteria for local treatment. However, accurate histological evaluation of the resected specimens is essential to avoid recurrence for such EGCs that should be cured.
\end{abstract}

Key words Early gastric cancer · Local treatment - Endoscopic mucosal resection - Incidence of lymph node metastasis

Offprint requests to: $\mathrm{M}$. Sasako

Received: October 26, 2000 / Accepted: December 19, 2000

\section{Introduction}

Endoscopic mucosal resection (EMR) is an accepted treatment for those early gastric cancers (EGC) associated with a minimal risk of regional lymph node (LN) metastasis $[1,2]$. EMR is currently considered appropriate for well differentiated lesions less than $2 \mathrm{~cm}$ in diameter without central ulceration. It is recognised that lymphatic-vascular involvement, ulcer formation, and tumor size above $3 \mathrm{~cm}$ are independent risk factors for LN metastasis in EGCs limited to the mucosa [3]. Several institutions have suggested that the indications for gastric EMR should be widened [4-6]. However, any revision of the indications must be based on the evaluation of a large number of cases to provide sufficient statistical power. We reviewed a large series of gastrectomies to propose a revised list of indications for local treatment, including EMR, of EGC.

\section{Patients and methods}

A total of 5265 patients who had undergone gastrectomy with LN dissection for EGC at the National Cancer Center Hospital and the Cancer Institute Hospital were studied; 3016 lesions (57.2\%) were intramucosal cancers and $2249(42.8 \%)$ penetrated the submucosa. Only $65(2.2 \%)$ intramucosal cancers were associated with regional lymph node metastases. In comparison, 402 cancers invading the submucosa $(17.9 \%)$ were associated with nodal metastases. The clinical and pathological features of the lesions were assessed by univariate analysis to determine which factors predicted the presence of nodal metastases.

The following features were looked at: sex; age; and tumor (location, macroscopic appearance, size, presence or absence of ulceration of the lesion, the two major histological types [differentiated or undifferentiated lesions], lymphatic-vascular involvement, and de- 
Table 1. Relationship between clinicopathological factors and lymph node (LN) metastasis in intramucosal cancer; univariate analysis results

\begin{tabular}{|c|c|c|c|c|c|}
\hline & \multirow[b]{2}{*}{ Total } & \multicolumn{3}{|c|}{ Status of LN metastasis } & \multirow[b]{2}{*}{$P$ value } \\
\hline & & Negative & Positive & Percent & \\
\hline \multicolumn{6}{|l|}{ Sex } \\
\hline M & 1676 & 1638 & 38 & 2.3 & \multirow{2}{*}{0.4087} \\
\hline $\mathrm{F}$ & 894 & 869 & 25 & 2.8 & \\
\hline \multicolumn{6}{|l|}{ Tumor location } \\
\hline $\mathrm{U}$ & 248 & 243 & 5 & 2.0 & \multirow[t]{3}{*}{0.7974} \\
\hline M & 1492 & 1453 & 39 & 2.6 & \\
\hline $\mathrm{L}$ & 830 & 811 & 19 & 2.3 & \\
\hline \multicolumn{6}{|l|}{ Macroscopic type } \\
\hline Elevated & 390 & 388 & 2 & 0.5 & \multirow[t]{2}{*}{0.0083} \\
\hline Depressed & 2048 & 1992 & 56 & 2.7 & \\
\hline \multicolumn{6}{|l|}{ Tumor size } \\
\hline$\leqq 10 \mathrm{~mm}$ & 357 & 353 & 4 & 1.1 & \multirow[t]{4}{*}{$<0.0001$} \\
\hline$\leqq 20 \mathrm{~mm}$ & 767 & 763 & 4 & 0.5 & \\
\hline$\leqq 30 \mathrm{~mm}$ & 927 & 917 & 10 & 1.1 & \\
\hline$>31 \mathrm{~mm}$ & 965 & 918 & 47 & 4.9 & \\
\hline \multicolumn{6}{|l|}{ Histological type } \\
\hline Differentiated & 1647 & 1640 & 7 & 0.4 & \multirow[t]{2}{*}{$<0.0001$} \\
\hline Undifferentiated & 1369 & 1311 & 58 & 4.2 & \\
\hline \multicolumn{6}{|l|}{ Ulcer findings } \\
\hline Absence & 1284 & 1278 & 6 & 0.5 & \multirow[t]{2}{*}{$<0.0001$} \\
\hline Presence & 1732 & 1673 & 59 & 3.4 & \\
\hline \multicolumn{6}{|c|}{ Lymphatic-vascular involvement } \\
\hline Absence & 2997 & 2937 & 60 & 2.0 & \multirow[t]{2}{*}{$<0.0001$} \\
\hline Presence & 19 & 14 & 5 & 26.3 & \\
\hline
\end{tabular}

Differentiated type includes papillary and tubular adenocarcinoma. Poorly differentiated adenocarcinoma and signet-ring cell carcinoma are classified as undifferentiated type

$\mathrm{U}$, Upper-third of stomach; M, middle-third of stomach; L, lower-third of stomach

gree of submucosal penetration). The Japanese classification of gastric carcinoma was used to classify the endoscopic appearance of the lesions [7]. Well and moderately differentiated tubular adenocarcinomas and papillary adenocarcinomas were grouped together as "differentiated lesions". Poorly differentiated adenocarcinomas and signet-ring cell carcinomas were classified as "undifferentiated histological types" [7]. Lesions with ulceration or scarring from previous ulceration (converging folds or deformity of the muscularis propria, or fibrosis in the submucosal or deeper layer) within them were regarded as "ulcerated lesions". The depth of submucosal invasion was measured from the muscularis mucosa to the point of deepest penetration. The depth of submucosal penetration was classified into two subgroups: SM1 $(\leqslant 500 \mu \mathrm{m}$ penetration into submucosa) and SM2 (>500 $\mu \mathrm{m})$. All histological sections were examined by three pathologists (Y.K., A.Y., and T.S.).

Statistical analysis was carried out using the SAS program (SAS Institute, Cary, NC, USA). The association of LN metastasis with clinicopathological variables was assessed using the simple $\chi$ test, with $P<0.01$ considered significant. The probability of LN metastasis was estimated with $95 \%$ confidence intervals (95\% CI), based on the exact binominal distribution.

\section{Results}

\section{Intramucosal cancer}

The relationship between different clinical and pathological factors and the risk of LN metastases is summarized in Table 1. Depressed or ulcerated lesions, larger than $30 \mathrm{~mm}$, of the undifferentiated histological type, with invasion into lymphatics or venules, were associated with an increased risk of nodal metastases. In contrast, none of the 1230 differentiated less than $30 \mathrm{~mm}$ in size, regardless of ulceration, were associated with metastases (95\% CI, $0-0.3 \%$ ) (Table 2). None of the 929 lesions without ulceration were associated with nodal metastases ( $95 \%$ CI, $0-0.4 \%$ ) regardless of the size of the lesion.

The overall risk of LN metastases in histologically undifferentiated lesions was $4.2 \%$. However, none of the 141 undifferentiated lesions without ulceration, less than $20 \mathrm{~mm}$ in size, were associated with positive lymph nodes $(95 \% \mathrm{CI}, 0-2.6 \%)$. 
Table 2. Lymph node metastasis in intramucosal cancer by tumor size and histological type $^{\mathrm{a}}$

All intramucosal cancers

\begin{tabular}{lrrrrrrrrr}
\hline & Total & LNM & $\%$ & Diff. & LNM & $\%$ & Undiff. & LNM & $\%$ \\
\hline$\leqq 10 \mathrm{~mm}$ & 357 & 4 & 1.1 & 257 & 0 & 0.0 & 100 & 4 & 4.0 \\
$\leqq 20 \mathrm{~mm}$ & 767 & 4 & 0.5 & 455 & 0 & 0.0 & 312 & 4 & 1.3 \\
$\leqq 30 \mathrm{~mm}$ & 927 & 10 & 1.1 & 518 & 0 & 0.0 & 409 & 10 & 2.4 \\
$>31 \mathrm{~mm}$ & 965 & 47 & 4.9 & 417 & 7 & 1.7 & 548 & 40 & 7.3 \\
Total & 3016 & 65 & 2.2 & 1647 & 7 & 0.4 & 1369 & 58 & 4.2 \\
\hline
\end{tabular}

Intramucosal cancer without ulcer findings

\begin{tabular}{lrrrrrrrrr}
\hline & Total & LN & $\%$ & Diff. & LNM & $\%$ & Undiff. & LNM & $\%$ \\
\hline $10 \mathrm{~mm}$ & 206 & 0 & 0.0 & 163 & 0 & 0.0 & 43 & 0 & 0.0 \\
$\leqq 20 \mathrm{~mm}$ & 372 & 0 & 0.0 & 274 & 0 & 0.0 & 98 & 0 & 0.0 \\
$\leqq 30 \mathrm{~mm}$ & 422 & 2 & 0.5 & 305 & 0 & 0.0 & 117 & 2 & 1.7 \\
$>31 \mathrm{~mm}$ & 284 & 4 & 1.4 & 187 & 0 & 0.0 & 97 & 4 & 4.1 \\
Total & 1284 & 6 & 0.5 & 929 & 0 & 0.0 & 355 & 5 & 1.4 \\
\hline
\end{tabular}

LNM, Lymph node metastasis; Diff, differentiated histological type; Undiff, undifferentiated histological type

${ }^{\text {a }}$ Lesions of differentiated type, limited to the mucosa, of size $\leqq 30 \mathrm{~mm}$, have minimal risk of LNM; incidence, 0/1230; 95\% confidence interval (CI), $0-0.3 \%$

Lesions of differentiated type, limited to the mucosa, without ulcerative findings, have little possibility of LNM; incidence, $0 / 929 ; 95 \%$ CI, $0-0.4 \%$

Lesions of undifferentated type, limited to the mucosa, without ulcerative findings, and a size of $\leq 20 \mathrm{~mm}$, have a small risk of LNM; incidence 0/141; <95\% CI, $0-2.6 \%$

\section{Submucosal invasive cancer}

Similarly to the findings for intramucosal cancers, there was a significant correlation between tumor size larger than $30 \mathrm{~mm}$ and lymphatic-vascular involvement with an increased risk of LN metastases. In addition, those cancers penetrating deeply into the submucosa were the most likely to be associated with regional LN metastases (Table 3). The relationship between LN metastasis and tumor characteristics such as size, depth of submucosal invasion, presence of ulceration, differentiation, and lymphatic or vascular permeation is shown in Table 4. For well differentiated tumors, subgroup analysis based on the pairing of individual factors such as tumor size, depth of submucosal penetration, and lymphatic-vascular involvement failed to yield a subgroup entirely free of nodal metastasis. However, the subgroup of 145 lesions with a size less than $30 \mathrm{~mm}$, well differentiated histology, lack of lymphatic-vascular invasion, and submucosal penetration of less than $500 \mu \mathrm{m}$ was entirely free of nodal metastasis $(95 \% \mathrm{CI}$, $0-2.5 \%)$.

\section{Discussion}

EGC is defined as that in which tumor invasion is confined to the mucosa or submucosa, irrespective of the presence of regional LN metastasis [7]. Because it is recognized that the presence of $\mathrm{LN}$ metastasis has a strong adverse influence on the prognosis of patients with EGC [8-10], radical surgery with the complete removal of the first and second tier LNs has become the gold standard treatment for patients with EGCs [1112], with 5-year survival rates being in excess of $90 \%$, including recent European series [10-16]. In our own series from the National Cancer Center in Japan, the 5 -year survival rates in patients with intramucosal and submucosal invasive cancers, excluding noncancerous deaths, were $99 \%$ and $96 \%$, respectively [14]. However, the incidence of $\mathrm{LN}$ metastasis in intramucosal and submucosal EGCs has been reported as approximately $3 \%$ and $20 \%$, respectively [17-23]; therefore, surgery may be excessive in many patients with these lesions. Considering the risks of gastrectomy and the negative effect on the patient's quality of life [24-29], if a group of patients with a negligible risk of LN metastasis can be defined, it is sensible to offer a local treatment for them.

EMR for selected intramucosal EGC, for which the possibility of LN metastasis is almost zero, has been widely accepted as a therapeutic strategy for cure in Japan. Currently, the accepted indications for EMR are: (1) well differentiated elevated lesions less than $20 \mathrm{~mm}$ in size, and (2) small ( $\leq 10 \mathrm{~mm}$ ) depressed well differentiated tumors without ulceration [30]. However, these 
Table 3. Relationship between clinicopathological factors and lymph node metastasis in submucosal invasive cancer; univariate analysis results

\begin{tabular}{|c|c|c|c|c|c|}
\hline & \multirow[b]{2}{*}{ Total } & \multicolumn{3}{|c|}{ Status of LN metastasis } & \multirow[b]{2}{*}{$P$ value } \\
\hline & & Negative & Positive & Percent & \\
\hline \multicolumn{6}{|l|}{ Sex } \\
\hline M & 1424 & 1173 & 251 & 17.6 & \multirow{2}{*}{0.0215} \\
\hline $\mathrm{F}$ & 629 & 491 & 138 & 21.9 & \\
\hline \multicolumn{6}{|l|}{ Tumor location } \\
\hline $\mathrm{U}$ & 619 & 501 & 118 & 19.1 & \multirow[t]{3}{*}{0.9402} \\
\hline M & 1028 & 836 & 192 & 18.7 & \\
\hline $\mathrm{L}$ & 406 & 327 & 79 & 19.5 & \\
\hline \multicolumn{6}{|l|}{ Macroscopic type } \\
\hline Elevated & 440 & 331 & 109 & 24.8 & \multirow[t]{2}{*}{0.0003} \\
\hline Depressed & 1505 & 1247 & 258 & 17.1 & \\
\hline \multicolumn{6}{|l|}{ Tumor size } \\
\hline$\leqq 10 \mathrm{~mm}$ & 114 & 105 & 9 & 7.9 & \multirow[t]{4}{*}{$<0.0001$} \\
\hline$\leqq 20 \mathrm{~mm}$ & 512 & 444 & 68 & 13.3 & \\
\hline$\leqq 30 \mathrm{~mm}$ & 677 & 572 & 105 & 15.5 & \\
\hline$>31 \mathrm{~mm}$ & 946 & 726 & 220 & 23.3 & \\
\hline \multicolumn{6}{|l|}{ Histological type } \\
\hline Differentiated & 1277 & 1060 & 217 & 17.0 & \multirow[t]{2}{*}{0.2110} \\
\hline Undifferentiated & 972 & 787 & 185 & 19.0 & \\
\hline \multicolumn{6}{|l|}{ Ulcer findings } \\
\hline Absence & 790 & 640 & 150 & 19.0 & \multirow[t]{2}{*}{0.9712} \\
\hline Presence & 1263 & 1024 & 239 & 18.9 & \\
\hline \multicolumn{6}{|c|}{ Lymphatic-vascular involvement } \\
\hline Absence & 1350 & 1218 & 132 & 9.8 & \multirow[t]{2}{*}{$<0.0001$} \\
\hline Presence & 703 & 446 & 257 & 36.6 & \\
\hline \multicolumn{6}{|c|}{ Degree of submucosal penetration } \\
\hline SM1 & 364 & 333 & 32 & 8.8 & \multirow[t]{2}{*}{$<0.0001$} \\
\hline SM2 & 1272 & 971 & 301 & 23.7 & \\
\hline
\end{tabular}

SM1, Penetration of submucosal layer less than $500 \mu \mathrm{m}$ from muscularis mucosa; SM2, penetration of $500 \mu \mathrm{m}$ or more

criteria are rather strict, and currently, many patients may be subjected to unnecessary surgery. Therefore many Japanese investigators have suggested possible extended criteria for local treatment (Table $5[3,5,31-$ $35])$. The upper limit of the $95 \%$ CI calculated from these reports, because of the small sample size, was too large to exclude the possibility of LN metastasis. Previous reviews have been based on smaller series, providing large confidence intervals when the risk of lymph node metastasis is being calculated. Based on our larger series of cases, we have been able to clarify the risks associated with different lesions further, and we propose an expansion of the criteria for local treatment (Table 6).

These criteria are based on complete histological examination of the resected specimen. The findings for some factors, especially lack of lymphatic-vascular involvement, or SM1 grade, which are associated with a minimal risk of LN metastasis, are available only after histological examination of the entire resected specimen. Therefore, it is of paramount importance that the specimen is resected in such a way that an accurate histological examination can be carried out.
When expansion of local treatment for patients with EGC is considered, it is essential to accurately evaluate the resected specimen to determine whether an additional surgical procedure is warranted. The method of local treatment varies among institutions, depending on the techniques used to make such evaluations.

There are several techniques for endoscopic mucosal resection. Korenaga et al. [17] reported that depth of penetration was difficult to assess correctly in lesions larger than $15 \mathrm{~mm}$ resected piecemeal. At the National Cancer Center, a new technique, using an insulatedtipped (IT) needle knife has been invented to allow the endoscopic en-bloc resection of larger lesions [36]. If resected en-bloc, even lesions larger than $15 \mathrm{~mm}$ can be examined as accurately as surgically resected material. With the IT knife, we are now offering EMR for many patients who would have been treated by surgical intervention.

It is difficult to determine clinically whether lesions are confined to the mucosa or whether they are likely to penetrate the submucosa. Reported series have indicated that the endoscopic assessment of depth of pen- 
Table 4. Lymph node metastasis by submucosal invasive cancer ${ }^{\mathrm{a}}$

All submucosal invasive cancers

\begin{tabular}{|c|c|c|c|c|c|c|c|c|c|}
\hline & Total & LNM & $\%$ & Diff. & LNM & $\%$ & Undiff. & LNM & $\%$ \\
\hline$\leqq 10 \mathrm{~mm}$ & 99 & 8 & 8.1 & 70 & 6 & 8.6 & 29 & 2 & 6.9 \\
\hline$\leqq 20 \mathrm{~mm}$ & 437 & 56 & 12.8 & 266 & 32 & 12.0 & 171 & 24 & 14.0 \\
\hline$\leqq 30 \mathrm{~mm}$ & 567 & 106 & 18.7 & 344 & 56 & 16.3 & 223 & 50 & 22.4 \\
\hline$>31 \mathrm{~mm}$ & 743 & 130 & 17.5 & 411 & 92 & 22.4 & 332 & 38 & 11.4 \\
\hline Total & 1846 & 300 & 16.3 & 1091 & 186 & 17.0 & 755 & 114 & 15.1 \\
\hline
\end{tabular}

Lymph node metastasis by tumor size and depth of submucosal penetration in tumors with differentiated histological type

\begin{tabular}{lrrrrrr}
\hline & SM1 & LNM & \% & SM2 & LNM & $\%$ \\
\hline $10 \mathrm{~mm}$ & 31 & 1 & 3.2 & 39 & 5 & 12.8 \\
$\leqq 20 \mathrm{~mm}$ & 71 & 4 & 5.6 & 195 & 28 & 14.4 \\
$\leqq 30 \mathrm{~mm}$ & 71 & 4 & 5.6 & 273 & 52 & 19.0 \\
$>31 \mathrm{~mm}$ & 92 & 6 & 6.5 & 319 & 86 & 27.0 \\
Total & 265 & 15 & 5.7 & 826 & 171 & 20.7 \\
\hline
\end{tabular}

Lymph node metastasis by tumor size and ulcer findings in tumors with differentiated histological type

\begin{tabular}{lrrrrrr}
\hline & ul- & LNM & \multicolumn{1}{c}{$\%$} & ul + & LNM & $\%$ \\
\hline $10 \mathrm{~mm}$ & 42 & 3 & 7.1 & 28 & 3 & 10.7 \\
$\leqq 20 \mathrm{~mm}$ & 140 & 13 & 9.3 & 126 & 19 & 15.1 \\
$\leqq 30 \mathrm{~mm}$ & 158 & 27 & 17.1 & 186 & 29 & 15.6 \\
$>31 \mathrm{~mm}$ & 188 & 44 & 23.4 & 223 & 48 & 21.5 \\
Total & 528 & 87 & 16.5 & 563 & 99 & 17.6 \\
\hline
\end{tabular}

Lymph node metastasis by tumor size and lymphatic-vascular involvement in tumors with differentiated histological type

\begin{tabular}{lrrrrrr}
\hline & Negative & LNM & $\%$ & Positive & LNM & $\%$ \\
\hline $10 \mathrm{~mm}$ & 56 & 3 & 5.4 & 14 & 3 & 21.4 \\
$\leqq 20 \mathrm{~mm}$ & 181 & 14 & 7.7 & 85 & 18 & 21.2 \\
$\leqq 30 \mathrm{~mm}$ & 202 & 14 & 6.9 & 142 & 42 & 29.6 \\
$>31 \mathrm{~mm}$ & 231 & 21 & 9.1 & 180 & 71 & 39.4 \\
Total & 670 & 52 & 7.8 & 421 & 134 & 31.8 \\
\hline
\end{tabular}

Lymph node metastasis by tumor size in SM1 differentiated tumors without lymphatic-vascular involvement

\begin{tabular}{lccc}
\hline & Number & LNM & $\%$ \\
\hline $10 \mathrm{~mm}$ & 28 & 0 & 0.0 \\
$\leqq 20 \mathrm{~mm}$ & 59 & 0 & 0.0 \\
$\leqq 30 \mathrm{~mm}$ & 58 & 0 & 0.0 \\
$>31 \mathrm{~mm}$ & 78 & 2 & 2.6 \\
Total & 223 & 2 & 0.9
\end{tabular}

LNM, Lymph node metastasis; Diff, differentiated histological type; Undiff, undifferentiated histological type; ul, histological ulcer findings ${ }^{a}$ When the tumor is of differentiated type, submucosal, showing no lymphatic-vascular permeation, and size is $30 \mathrm{~mm}$ or less, the incidence of LNM is $0 \%(0 / 145 ; 95 \% \mathrm{CI}, 0-2.5 \%)$. Only this subgroup should be considered for local treatment

etration is inaccurate in up to $20 \%$ of lesions [37,38]. Biopsies are too superficial to provide this information, but EMR provides a larger specimen, which allows assessment of depth of invasion and lymphatic-vascular involvement. Considering that the pretreatment diag- nosis could be incorrect for $20 \%$ of the tumors that are candidates for local treatment, it is essential to make an accurate histological evaluation of the resected specimens to avoid recurrence of such early lesions that should be cured. 
Table 5. Investigation of extended EMR criteria

\begin{tabular}{|c|c|c|c|}
\hline Author & Criteria & Incidence & $95 \% \mathrm{CI}$ \\
\hline Yamao [3] & $\begin{array}{l}\text { Intramucosal cancer, no lymphatic-vascular invasion, without ulcer } \\
\text { findings, tumor less than } 3 \mathrm{~cm} \text { in size }\end{array}$ & $1 / 277 ; 0.36 \%$ & $0.009 \%-1.99 \%$ \\
\hline \multirow[t]{2}{*}{ Hiki [31] } & Intramucosal elevated lesion, tumor less than $2.5 \mathrm{~cm}$ in size & $0 / 21 ; 0 \%$ & $0-16.1 \%$ \\
\hline & $\begin{array}{l}\text { Intramucosal depressed lesion, without ulcer findings, tumor less than } \\
2 \mathrm{~cm} \text { in size }\end{array}$ & $0 / 113 ; 0 \%$ & $0-3.2 \%$ \\
\hline Ohgami [32] & Intramucosal protruded lesion, tumor less than $2.5 \mathrm{~cm}$ in size & $0 / 67 ; 0 \%$ & $0-5.4 \%$ \\
\hline Yasuda [5] & $\begin{array}{l}\text { Submucosal invasive cancer less than } 300 \mu \mathrm{m} \text { in depth, tumor less } \\
\text { than } 1 \mathrm{~cm} \text { in size }\end{array}$ & $0 / 12 ; 0 \%$ & $0-26.5 \%$ \\
\hline Oizumi [33] & Submucosal invasive cancer, tumor less than $1 \mathrm{~cm}$ in size & $0 / 28 ; 0 \%$ & $0-12.3 \%$ \\
\hline Fujii [34] & Submucosai invasive cancer, tumor less than $1 \mathrm{~cm}$ in size & $0 / 14 ; 0 \%$ & $0-23.2 \%$ \\
\hline Gotoda [35] & $\begin{array}{l}\text { Differentiated adenocarcinoma, no lymphatic-vascular invasion, tumor } \\
\text { less than } 3 \mathrm{~cm} \text { in size, submucosal invasive cancer less than } \\
500 \mu \mathrm{m} \text { in depth }\end{array}$ & $0 / 117 ; 0 \%$ & $0-3.1 \%$ \\
\hline
\end{tabular}

EMR, Endoscopic mucosal resection

Table 6. Criteria for expansion of local treatment, derived from our results

\begin{tabular}{|c|c|c|}
\hline Criteria & Incidence & $95 \% \mathrm{CI}$ \\
\hline $\begin{array}{l}\text { Intramucosal cancer } \\
\text { differentiated adenocarcinoma, no lymphatic-vascular invasion, irrespective of } \\
\text { ulcer findings, tumor less than } 3 \mathrm{~cm} \text { in size }\end{array}$ & $0 / 1230 ; 0 \%$ & $0-0.3 \%$ \\
\hline $\begin{array}{l}\text { Intramucosal cancer } \\
\text { differentiated adenocarcinoma, no lymphatic-vascular invasion, without ulcer } \\
\text { findings, irrespective of tumor size }\end{array}$ & 0/929; 0\% & $0-0.4 \%$ \\
\hline $\begin{array}{l}\text { Undifferentiated intramucosal cancer } \\
\text { no lymphatic-vascular invasion, without ulcer findings, tumor less than } 3 \mathrm{~cm} \\
\text { in size }\end{array}$ & $0 / 141 ; 0 \%$ & $0-2.6 \%$ \\
\hline $\begin{array}{l}\text { Minute submucosal penetration (SM1) } \\
\text { differentiated adenocarcinoma, no lymphatic-vascular invasion, tumor less than } \\
3 \mathrm{~cm} \text { in size }\end{array}$ & $0 / 145 ; 0 \%$ & $0-2.5 \%$ \\
\hline
\end{tabular}

Acknowledgments We thank Professor A.T.R. Axon and Dr. B. Rembacken (Gastroenterology Unit, General Infirmary at Leeds, UK) for their special advice in regard to the preparation of this manuscript, and we thank Drs. D. Saito, T. Sano, H. Katai, and K. Maruyama for their invaluable comments. We very much appreciate the help of Dr. H. Fukuda in regard to suggestions for the statistical analyses.

\section{References}

1. Kato $\mathrm{Y}$, Yanagisawa A, Utsude $\mathrm{T}$, Kubo $\mathrm{K}$, Yokokawa $\mathrm{K}$, Takekoshi T, et al. Safer and more reliable endoscopic mucosal resection in the treatment of early gastric carcinomas - from a pathological standpoint (in Japanese with English abstract). Gastroenterol Endosc 1993;5:1153-9.

2. Takekoshi T, Takagi K, Kato Y. Radical endoscopic treatment of early gastric cancer. Gann Monogr Cancer Res 1990;37:111-26.

3. Yamao T, Shirao K, Ono H, Kondo H, Saito D, Yamaguchi H, et al. Risk factors for lymph node metastasis from intramucosal gastric carcinoma. Cancer 1996;77:602-6.
4. Tsuchiya A, Kikuchi Y, Ando Y, Yoshida T, Abe R. Lymph node metastases in gastric cancer invading the submucosal layer. Eur J Surg Oncol 1995;21:248-50.

5. Yasuda K, Shiraishi N, Suematsu T, Yamaguchi K, Adachi Y, Kitano S. Rate of detection of lymph node metastasis is correlated with the depth of submucosal invasion in early stage gastric carcinoma. Cancer 1999;85:2119-23.

6. Nakano K, Yanagisawa A, Utsude T, Kubo K, Kato Y. Limits of indication of endoscopic mucosal resection (EMR) for treatment of early gastric carcinoma of undifferentiated type - from a pathological viewpoint (in Japanese with English abstract). Stomach and Intestine 1995;30:1289-94.

7. Japanese Gastric Cancer Association. Japanese classification of gastric carcinoma. 2nd English Ed. Gastric Cancer 1998;1:1024.

8. Itoh H, Oohata Y, Nakamura K, Nagata T, Mibu R, Nakayama F. Complete 10-year postgastrectomy follow-up of early gastric cancer. Am J Surg 1989;158:14-16.

9. Shiu MH, Moore E, Sanders M, Huvos A, Freedman B, Goodbold $\mathbf{J}$, et al. Influence of extent of resection on survival after curative treatment of gastric carcinoma. Arch Surg 1987;122: 1347-51.

10. Sano T, Sasako M, Kinoshita T, Maruyama K. Recurrence of early gastric cancer. Follow-up of 1475 patients and review of Japanese literature. Cancer 1993;72:3174-8. 
11. Maruyama K, Okabayashi K, Kinoshita T. Progress in gastric cancer surgery in Japan and its limits of radicality. World J Surg 1987;11:418-25.

12. Okamura T, Tsujitani S, Korenaga D, Haraguchi M, Baba H, Hiramoto Y, et al. Lymphadenectomy for cure in patients with early gastric cancer and lymph node metastasis. Am J Surg 1988:155:476-80.

13. Noguchi Y, Imada T, Matsumoto A, Coit DG, Brennan MF. Radical surgery for gastric cancer: a review of Japanese experience. Cancer 1989;64:2053-62.

14. Sasako M, Kinoshita T, Maruyama K. Prognosis of early gastric cancer (in Japanese with English abstract). Stomach and Intestine 1993;28(Suppl):139-46.

15. Sue-Ling HM, Martin IG, Griffith J, Ward DC, Quirke P, Dixon MF, et al. Early gastric cancer: 46 cases treated in one surgical department. Gut 1992;33:1318-22.

16. Sue-Ling HM, Johnston D, Martin IG, Dixon MF, Lansdown MRJ, McMahon MJ, et al. Gastric cancer: a curable disease in British. BMJ 1993;307:591-6.

17. Korenaga D, Haraguchi M, Tsujitani S, Okamura T, Tamada R, Sugimachi K. Clinicopathological features of mucosal carcinoma of the stomach with lymph node metastasis in 11 patients. Br J Surg 1986;73:431-3.

18. Iriyama $\mathrm{K}$, Asakawa $\mathrm{T}$, Koike $\mathrm{H}$, Nishiwaki $\mathrm{H}$, Suzuki $H$. Is extensive lymphadenectomy necessary for surgical treatment of intramucosal carcinoma of the stomach? Arch Surg 1989;124:30911.

19. Inoue K, Tobe T, Kan N, Nio Y, Sakai M, Takeuchi E, et al. Problems in the definition and treatment of early gastric cancer. Br J Surg 1991;78:818-21.

20. Maehara Y, Orita H, Okuyama T, Moriguchi S, Tsujitani S, Korenaga D, et al. Predictors of lymph node metastasis in early gastric cancer. Br J Surg 1992;79:245-7.

21. Sano T, Kobori O, Muto T. Lymph node metastasis from early gastric cancer: endoscopic resection of tumour. Br J Surg 1992; 79:241-4.

22. Hanazaki K, Wakabayashi M, Sodeyama H, Miyazawa M, Yokoyama S, Sode Y, et al. Clinicopathologic features of submucosal carcinoma of the stomach. J Clin Gastroenterol 1997;24: $150-5$.

23. Kitamura K, Yamaguchi T, Taniguchi H, Hagiwara A, Sawai K, Takahashi T. Analysis of lymph node metastasis in early gastric cancer: rationale of limited surgery. J Surg Oncol 1997;64:42-7.

24. Sasako M. Risk factors for surgical treatment in the Dutch gastric cancer trial. Br J Surg 1997;84:1567-71.

25. Davies J, Johnston D, Sue-Ling HM, Young S, May J, Griffith J, et al. Total or subtotal gastrectomy for gastric carcinoma? A study of quality of life. World J Surg 1998;22:1048-55.
26. Jentschura D, Winkler M, Strohmeier N, Rumstadt B, Hagmuller E. Quality of life after curative surgery for gastric cancer: a comparison between total gastrectomy and subtotal gastrectomy resection. Hepatogastroenterology 1997;44:1137-42.

27. Jatzko GR, Lisborg PH, Denk H, Klimpfinger M, Stettner HM. A 10-year experience with Japanese-type lymph node dissection for gastric cancer outside of Japan. Cancer 1995;76:1302-12.

28. Bonenkamp JJ, Songun I, Hermans J, Sasako M, Welvaart K, Plukker JTM, et al. Randomised comparison of morbidity after D1 and D2 dissection for gastric cancer in 996 Dutch patients. Lancet 1995;345:745-8.

29. Cuschieri A, Fayers P, Fielding J, Craven J, Bancewicz J, Joypaul $\mathrm{V}$, et al. Postoperative morbidity and mortality after D1 and D2 resection for gastric cancer: preliminary results of the MRC randomised controlled surgical trial. Lancet 1996;347:995-9.

30. Tsujitani S, Oka S, Saito H, Kondo A, Ikeguchi M, Maeta M, Kaibara N. Less invasive surgery for early gasric cancer based on the low probability of lymph node metastasis. Surgery 1999;125: $148-54$.

31. Hiki Y. Endoscopic mucosal resection (EMR) for early gastric cancer (in Japanese with English abstract). Jpn J Surg 1996;97: 273-8.

32. Ohgami M, Otani $\mathrm{Y}$, Kumai K, Kubota T, Kitajima $\mathrm{M}$. Laparoscopic surgery for early gastric cancer (in Japanese with English abstract). Jpn J Surg 1996;97:279-85.

33. Oizumi H, Matsuda T, Fukase K, Furukawa A, Mito S, Takahashi K. Endoscopic resection for early gastric cancer: the accrual procedure and clinical evaluation (in Japanese with English abstract). Stomach and Intestine 1991;26:289-300.

34. Fujii K, Okajima K, Isozaki H, Hara H, Nomura E, Sako S, et al. A clinicopathological study on the indications of limited surgery for submucosal gastric cancer (in Japanese with English abstract). Jpn J Gastroenterol Surg 1998;31:2055-62.

35. Gotoda T, Sasako M, Shimoda T, Ono H, Katai H, Sano T. An evaluation of the necessity of gastrectomy with lymph node dissection for patients with submucosal invasive gastric cancer. Br J Surg (in press).

36. Gotoda T, Kondo H, Ono H, Saito Y, Yamaguchi H, Saito D, et al. A new endoscopic mucosal resection (EMR) procedure using an insulation-tipped diathermic (IT) knife for rectal flat lesions. Gastrointest Endosc 1999;50:560-3.

37. Sano T, Okuyama Y, Kobori O, Shimizu T, Morioka Y. Early gastric cancer. Endoscopic diagnosis of depth of invasion. Digest Dis Sci 1990;35:1335-40.

38. Ohashi S, Segawa K, Okumura S, Mitake M, Urano H, Shimodaira M, et al. The utility of endoscopic ultrasonography and endoscopy in the endoscopic mucosal resection of early gastric cancer. Gut 1999;45:599-604. 